Research Paper

\title{
Quantification of residual crystallinity in ball milled commercially sourced lactose monohydrate by thermo-analytical techniques and terahertz spectroscopy
}

\author{
Geoff Smith $^{\mathrm{a}, *}$, Amjad Hussain ${ }^{\mathrm{a}}$, Nadeem Irfan Bukhari ${ }^{\mathrm{b}}$, Irina Ermolina ${ }^{\mathrm{a}}$ \\ ${ }^{a}$ Leicester School of Pharmacy, De Montfort University, Leicester, United Kingdom \\ ${ }^{\mathrm{b}}$ University College of Pharmacy, University of the Punjab, Lahore, Pakistan
}

\section{A R T I C L E I N F O}

\section{Article history:}

Received 20 July 2014

Revised 11 February 2015

Accepted in revised form 26 February 2015

Available online 14 March 2015

\section{Keywords:}

Ball milling

Thermal techniques

Terahertz time domain spectroscopy

Amorphous

Quantification

Relative residual crystallinity

\begin{abstract}
A B S T R A C T
The quantification of crystallinity is necessary in order to be able to control the milling process. The use of thermal analysis for this assessment presents certain challenges, particularly in the case of crystal hydrates. In this study, the residual crystallinity on ball milling of lactose monohydrate (LMH), for periods up to $90 \mathrm{~min}$, was evaluated by thermo-analytical techniques (TGA, DSC) and terahertz spectroscopy $(\mathrm{THz})$. In general, the results from one of the DSC analysis and the $\mathrm{THz}$ measurements agree showing a monotonous decrease in relative residual crystallinity with milling time $(\sim 80 \%$ reduction after 60 min milling) and a slight increase at the 90 min time point. However, the estimates from TGA and two other methods of analyzing DSC curve do not agree with the former techniques and show variability with significantly higher estimates for crystallinity. It was concluded that, the thermal techniques require more complex treatment of the data in the evaluation of changes in crystallinity of a milled material (in particular to account for the de-vitrification and mutarotation of the material that inevitably occurs during the measurement cycle) while the analysis of $\mathrm{THz}$ data is more straightforward, with the measurement having no impact on the native state of the material.
\end{abstract}

(c) 2015 Elsevier B.V. All rights reserved.

\section{Introduction}

Milling is one of the conventional methods used in pharmaceutical technology for the reduction of particle size [1]. Among the various milling methods, ball milling is possibly the most aggressive technique, resulting in significant damage to the crystalline particles and a partial conversion to the amorphous state, the extent of which depends on the frequency and time of milling. The amorphous phase has the advantage of increased solubility and dissolution rate $[2,3]$. However, the process of milling inevitably leaves some crystals in a partially damaged state that provide seeds for de-vitrification, resulting in the potential loss of the

Abbreviations: THz-TDS, terahertz time domain spectroscopy; THz, terahertz; DVS, dynamic vapor sorption; NIR, near infrared; DSC, Differential Scanning Calorimetry; TGA, thermogravimetric analysis; PXRD, powder X-ray diffraction; PLS, partial least square; LMH, lactose monohydrate; SEM, scanning electron microscopy; RRC, relative residual crystallinity.

* Corresponding author at: Pharmaceutical Technologies, School of Pharmacy, De Montfort University, The Gateway, Leicester LE1 9BH, United Kingdom. Tel.: +44 116250 6298, mobile: +44 (0) 77899 21406; fax: +44 1162577270 .

E-mail address: gsmith02@dmu.ac.uk (G. Smith). additional advantage conferred by the amorphous phase and creating a stability issue during shelf life of the product [4].

The quantification of this crystalline/amorphous content at various milling times, and over a range of ball-oscillation frequencies, is important in order to be able to control the milling process as well as explaining the impact of milling on solubility and dissolution rate and thereby investigating the stability of the material during storage.

The techniques commonly employed for quantification of crystalline materials, include DVS, isothermal micro-calorimetry, DSC, hyper-DSC, NIR, Raman spectroscopy and PXRD. Some of these are based on the analysis of the crystalline phase (PXRD, NIR) whereas others (Hyper-DSC, DVS and Microcalorimetry) are based on the analysis of the amorphous phase, while DSC can determine both crystalline and amorphous phases.

DVS is based on water vapor sorption and may give misleading results for materials in which the crystals also sorb water, alongside the amorphous phase under scrutiny. Organic vapor sorption is a possible alternative method [5] but this technique is not universal in its application. Isothermal micro-calorimetry detects the heat associated with the sorption of water by the amorphous phase 
but it requires crystallization of the amorphous to be favored kinetically [6]. PXRD might be considered as gold standard for crystallinity estimation but the results are inconsistent as it requires the preferred orientation of crystals in the path of beam, therefore whole pattern fitting is required for the complete characterization of a powder [7]. Measurement by Raman spectroscopy can induce photo-chemical reaction in the materials. In NIR, amorphization is inferred from a shift in the baseline of the spectral region rather than any change in the specific absorption peaks [8], therefore the first or second derivative of spectra is taken for quantification [9]. In addition, the NIR measurements are influenced by moisture [7]. Although both these vibrational techniques (Raman and NIR) are sensitive and quick methods, each require a calibration curve to be constructed from known crystalline and amorphous mixtures [10].

TGA measures the weight change associated with the loss of adsorbed water (if any) and the water of crystallization, in the case of a hydrated material. From the weight of the latter, the changes in crystallinity in milled hydrated materials may be estimated $[11,12]$. In order to use the TGA technique, one has to assume that the water of hydration in the residual crystalline material (within the milled material) provides an opportunity to quantify the proportion of un-damaged crystalline material remaining. However, there is always the possibility that the hydration water of the partially compromised crystalline particles will behave differently to the material in its native state, resulting in some uncertainty in the estimates of crystallinity so derived.

DSC is routinely used for the analysis of crystalline/amorphous materials. The quantification of crystallinity may be determined from the analysis of either the crystalline form or the amorphous state. The endothermic event associated with the melting of the crystalline phase that remains post milling may be used to determine the change in crystallinity on milling. However, the presence of an amorphous phase in a milled material may also manifest in the curve as a step in the baseline (indicating a glass transition) and/or exothermic peak in the curve (indicating a de-vitrification event). This devitrified amorphous phase will then contribute to the enthalpy of melting. Therefore one must subtract this contribution from the enthalpy of crystallization, in order to calculate the crystalline content of the milled material prior to analyzing the DSC curve.

In addition one should also recognize that milling may also result in defected or partially compromised crystals along with the amorphized phase and yet, the principle assumption is that, the specific enthalpy of melting of the defected crystalline material is the same as that of the starting material and is not impacted by the milling process.

Terahertz time domain spectroscopy (THz-TDS) produces pulses in the femtosecond time scale and therefore has the ability to probe crystal lattice and hydrogen bonding vibrations, which occur at frequencies in the low terahertz region $(0.1-4 \mathrm{THz})$. The intensity of the specific absorption peaks can be used to quantity the degree of crystallinity in a mixed phase system. This technique has been used previously for the characterization [13] and quantification [14] of the crystallinity of APIs. Also, it has been employed to differentiate hydrated and anhydrous forms [15] and for studying the dehydration process in various pharmaceuticals [16]. This technique has been used recently for the measurement of crystallinity in amino acids [17] and freeze dried sugars [18]. The benefit of this technique is that one can analyze the material in its native state.

Lactose monohydrate (LMH) is one of the most commonly used excipients in the pharmaceutical industry. Its main use is as a diluent in tablet formulations and as a carrier in dry powder inhalers [19]. The milling of LMH not only reduces its particle size but may also impact its hydration status, moreover, the raised temperature during the course of milling may cause instability in the amorphous phase that results in the anomeric transition of crystalline lactose [20]. There is therefore a need for a technique that could analyze a milled hydrated material in its native state. In this paper, a reliable method for determining the residual crystallinity (in respect to specific anomeric form, i.e. alpha lactose) in milled $\mathrm{LMH}$, in its native state, is researched and compared that to the thermal methods in an attempt to highlight the issues related with the latter techniques for quantification of the residual crystallinity of milled LMH. The LMH studied in this work is taken from a commercial source and therefore there is inevitably a proportion of the sample which will be in the form of beta lactose. Typically the beta lactose content can be between 3 and 4 percent [21]. The residual crystallinities quoted through this article are therefore stated as a relative measure of the change in crystallinity from the original starting material. To that end the term relative residual crystallinity (RRC) has been adopted through this article.

\section{Materials and methods}

Lactose monohydrate (EP/BP) was sieved at room temperature $\left(\sim 23^{\circ} \mathrm{C}\right)$ and $45 \%$ relative humidity. The particles that pass through a 80 mesh sieve and retained on a 100 mesh sieve, were taken for analysis (corresponding to a linear size between 150 and $180 \mu \mathrm{m}$ ). The measured average particle size by SEM was $\sim 172 \mu \mathrm{m}$. Laser diffraction technique has shown that $50 \%$ of particles $\left(d_{50}\right)$ were of the size less than $154 \mu \mathrm{m}$.

\subsection{Ball milling}

The material was milled in the oscillatory ball mill (MM 301, Retsch, Germany) equipped with two $50 \mathrm{ml}$ stainless steel cylindrical jars each containing one stainless steel ball of $25 \mathrm{~mm}$ diameter. A weight of $2.5 \mathrm{~g}$ of LMH was loaded into each jar, which were then closed tightly and clamped in position of the mill. The mill was operated at frequency of $18 \mathrm{~Hz}$ for $5,10,15,30,45,60$ and $90 \mathrm{~min}$. The sample was collected into a glass bottle and immediately used for thermal and terahertz analysis.

Note: The mill frequency of $18 \mathrm{~Hz}$ was selected after an initial screening of three speeds i.e. 15,18 and $25 \mathrm{~Hz}$ as previously used by [22] based on the fact that this frequency had a significant impact on crystallinity without a marked increase in the temperature of the mill. The temperature of milled material was $\sim 40^{\circ} \mathrm{C}$, estimated by the insertion of a thermocouple probe into the powder immediately after milling.

\subsection{Thermogravimetric analysis (TGA)}

Thermogravimetric analysis (TGA) of un-milled and milled materials was carried out in a TGA instrument with auto-sampler system (Perkin Elmer, US) according to the method already described by [23]. The empty aluminum pan was loaded into the TGA instrument and tarred. Then the sample was placed in the pan and the pan returned to the instrument. The weight of sample was recorded in the temperature range from $25^{\circ} \mathrm{C}$ to $250{ }^{\circ} \mathrm{C}$ at the rate of $20^{\circ} \mathrm{C} \mathrm{min}^{-1}$.

\subsection{Differential Scanning Calorimetry (DSC)}

DSC experiments were performed according to method described in [23] using a Jade DSC (Perkin Elmer, US). The heating rate and heat flow were calibrated at $20^{\circ} \mathrm{C} \mathrm{min}-1$ using indium and zinc standard. Approximately $7 \mathrm{mg}$ sample was taken in a $50 \mu \mathrm{L}$ aluminum pans, sealed non-hermetically with perforated lids for the evaporation of water and then loaded in the analyzer by the 
auto-sampler. All samples were analyzed over the temperature range $25-250^{\circ} \mathrm{C}$, at the heat flow rate of $20^{\circ} \mathrm{C} \mathrm{min}-1$, applying the calibration acquired at $20^{\circ} \mathrm{C} \mathrm{min}^{-1}$. The residual crystalline content was calculated from the enthalpy of melting and/or crystallization or from desorption of the water of crystallization.

\subsection{Terahertz time domain spectroscopy (THz-TDS)}

\subsubsection{Sample preparation}

The samples for $\mathrm{THz}$ measurement were prepared by mixing polyethylene (PE) powder with the un-milled LMH (at concentrations of $4 \%, 6 \%, 8 \%, 10 \%$ and $12 \% \mathrm{w} / \mathrm{w})$ or milled $\mathrm{LMH}(10 \% \mathrm{w} / \mathrm{w})$. PE powder was provided by Teraview, UK and used for the $\mathrm{THz}$ blank. The powders were geometrically mixed at room
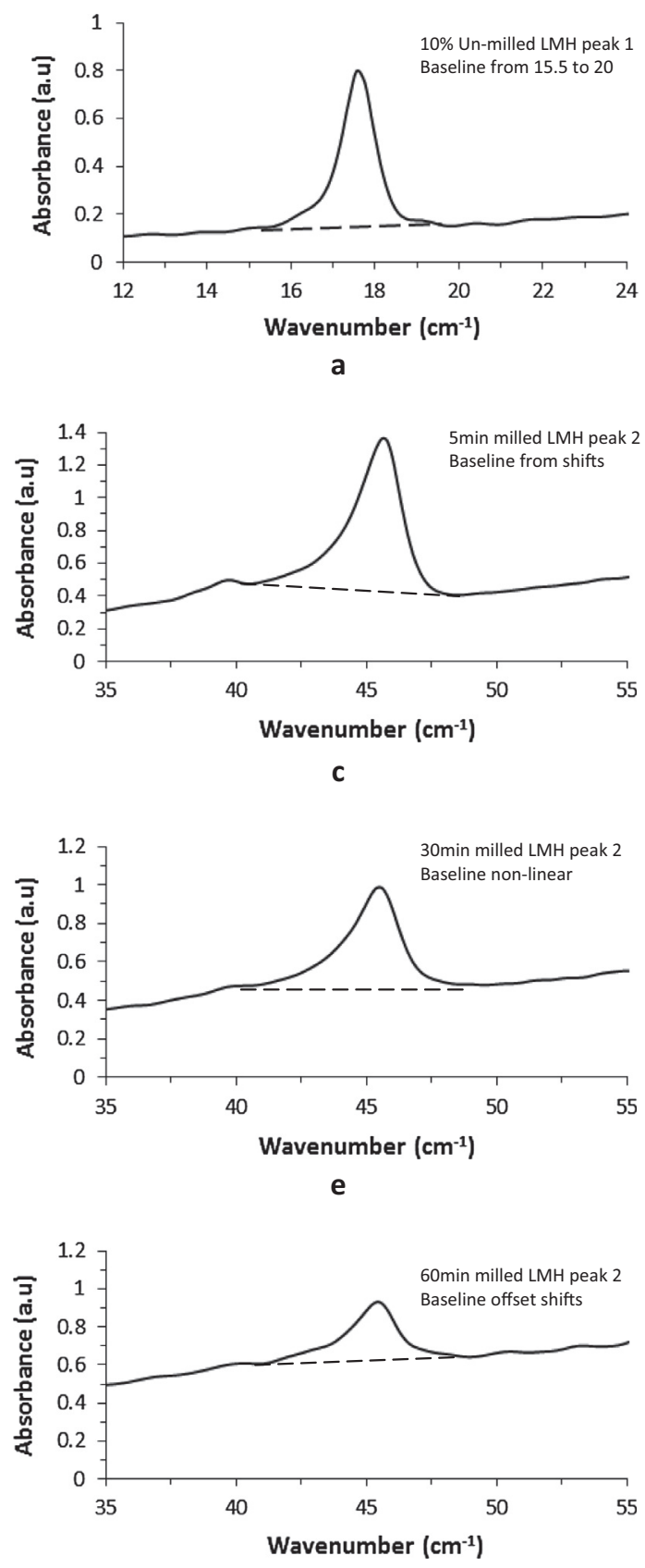

g temperature and humidity conditions to form a homogenous mixture and then pressed into disk shaped pellets using Gamlen Tablet Press (CT5, Gamlen Tableting Nottingham, UK) applying a compaction force of $500 \mathrm{~kg}$. The weight of each pellet was $\sim 400 \mathrm{mg}$ and the thickness $3.80 \pm 0.08 \mathrm{~mm}$. The same weight pellets containing $100 \%$ PE were also prepared to act as a reference.

\subsubsection{Terahertz measurements}

The $\mathrm{THz}$ spectra were acquired in transmission mode by a $\mathrm{THz}$ TDS Spectra-3000 (Teraview Limited, UK). Each terahertz spectrum was obtained by averaging 900 scans, with a frequency of 30 scans per second and a spectral resolution of $1.2 \mathrm{~cm}^{-1}$. The reference pellet (PE alone) and all samples were individually placed in a $13 \mathrm{~mm}$ (diameter) sample holder which was then placed at the focal point

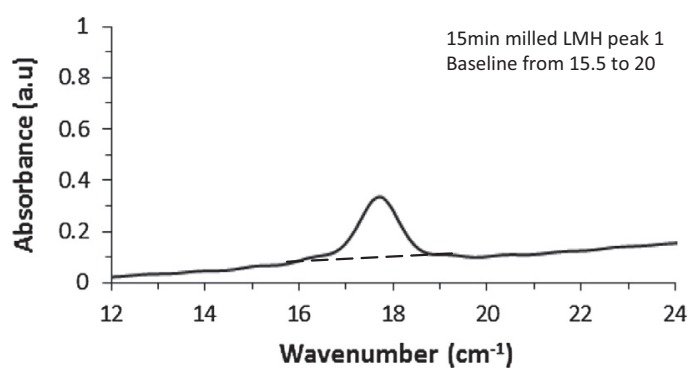

b

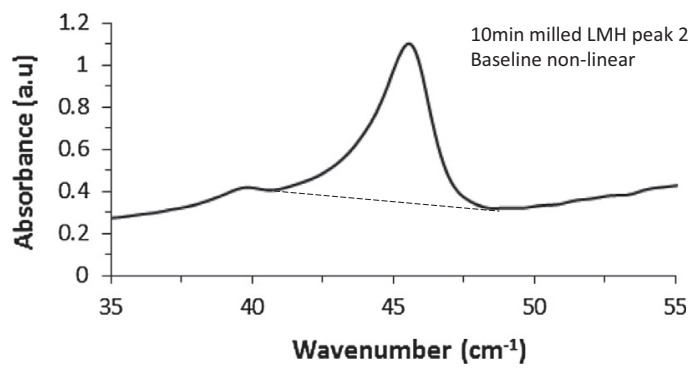

d
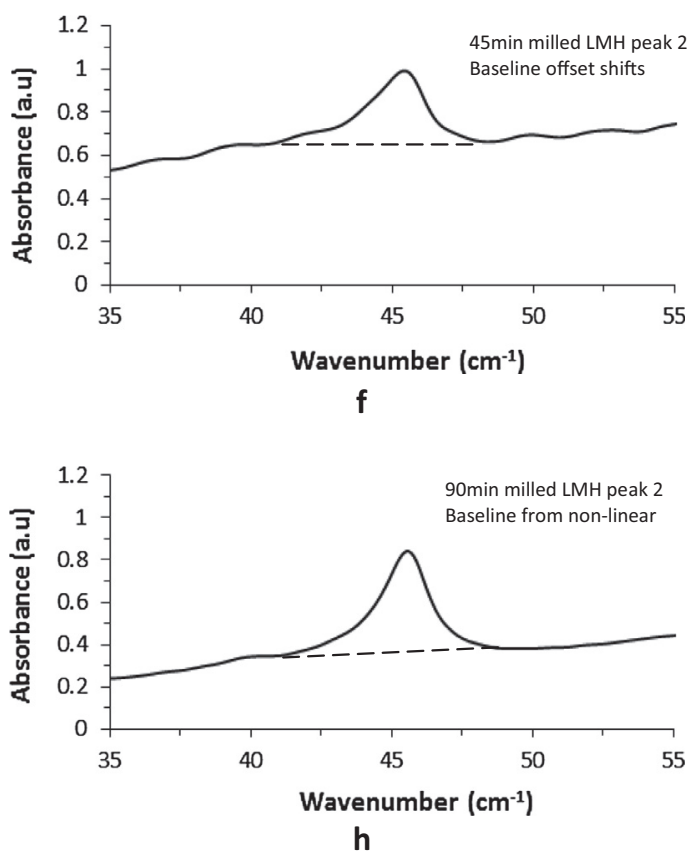

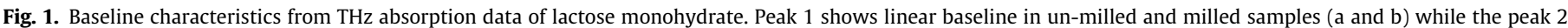
shows a non-linear baseline in milled samples $(\mathrm{c}-\mathrm{h})$ in terms of shifts in gradient and offset with milling time. 
of the THz beam. The atmosphere in the sample holder compartment was dried by purging with nitrogen gas for 10 min prior to and during each measurement.

All samples were prepared in triplicate. The $\mathrm{THz}$ spectrum of each pellet was measured at three different points across its diameter and a mean was taken of the resultant 9 measurements $(n=9)$.

\subsubsection{Quantitative analysis}

The $\mathrm{THz}$ spectral region (between $20 \mathrm{~cm}^{-1}$ and $60 \mathrm{~cm}^{-1}$ ) for quantitative analysis was selected based on the largest spectral difference between the spectrum of the reference (PE) and the spectra of LMH incorporated in PE. The spectra were analyzed by a conventional method, based on the estimation of area under absorption peak, as well as by a multivariate method. It was recognized that accuracy of the former method, which does not account for the equipment noise and other external variables, is dependent on the estimation of baseline of the peak (see Fig. 1a and b). The multivariate analysis applied here was based on partial least square (PLS) regression. Unlike the univariate peak area analysis approach, this method identifies a number of prediction variables and scores each as a different principal component. The component with the highest score is the factor that contributes most to the observations. Multivariate chemo-metric analysis has been used previously for calculation of crystallinity of from NIR data [24] and $\mathrm{THz}$ data [17].

\subsubsection{Peak selection for quantitative analysis}

Among the two $\mathrm{THz}$ peaks of alpha lactose (as described in Section 3.3.1), the first peak is sharp, with well-defined start and end points and has an approximately linear baseline in both the un-milled and milled samples (Fig. $1 \mathrm{a}$ and $\mathrm{b}$ ). The second peak shows more scattering (Fig. 1c-h) and presents difficulties in clearly defining the baseline which could lead to an under or overestimate of the residual crystallinity post milling. Therefore peak 1 was selected for quantitative analysis of alpha lactose. The same region of $\mathrm{THz}$ spectrum was used previously for studying the crystallization process in amorphous lactose monohydrate [25].
2.4.5. Area under the peak and construction of the calibration model

$\mathrm{THz}$ absorption spectra for different concentrations (4\%, 6\%, $8 \%$, $10 \%$ and $12 \% \mathrm{w} / \mathrm{w}$ ) of un-milled LMH were measured in the frequency range of $0-100 \mathrm{~cm}^{-1}$. The area under the absorption peak (peak 1) was then calculated by a trapezoidal method, following subtraction of a linear baseline between the start and end points of the peak (Fig. 2a) and used to construct a calibration curve (Fig. 2b). It is worth mentioning that in the cases where $\mathrm{THz}$ measurements are made as a function of increasing temperatures or humidity, an increase in the baseline absorption occurs which can described (and compensated for) by a power law function $[25,26]$. A power law function was not considered to be necessary in our case, given that the linear baseline provided a straight line calibration curve with a $R^{2}$ value of 0.9932 and a RMSE of $0.23 \%$ (Table 1). The linear function parameters of this calibration curve were then used to calculate the concentration of crystalline material remaining in the milled materials.

\subsubsection{Partial least square method and construction of calibration model}

The multivariate calibration model was constructed using unprocessed $\mathrm{THz}$ absorption data of peak 1 at different concentrations $(4 \%, 6 \%, 8 \%, 10 \%$ and $12 \% \mathrm{w} / \mathrm{w})$ of un-milled lactose. A PLS algorithm was applied using the Matlab software and a model with 4 latent variables was selected. The selected model demonstrated good agreement between predicted and actual concentrations (Fig. 3) and the PLS regression coefficients (often denoted 'Beta' coefficients) were then used to calculate the $\%(\mathrm{w} / \mathrm{w})$ relative crystallinity remaining in milled samples from the measured $\mathrm{THz}$ spectra.

The limit of detection (LOD) and limit of quantification (LOQ) are calculated from the following Eqs. (1) and (2), and the output (Table 1 ) values are used to compare the quality of each model.

LOD $=3.3 *$ RMSE

$\mathrm{LOQ}=10 * \mathrm{RMSE}$

RMSE is root mean square error calculated from AUC data or PLS regression.

Table 1

Values of LOD and LOQ as calculated from AUC and PLS predictive models of THz data.

\begin{tabular}{|c|c|c|c|c|c|c|}
\hline & \multicolumn{3}{|c|}{ Area of peak method } & \multicolumn{3}{|c|}{ Partial least square } \\
\hline & RMSE & LOD (w/w\%) & LOQ (w/w\%) & RMSE & LOD (w/w\%) & LOQ (w/w\%) \\
\hline Lactose monohydrate (peak 1 ) & 0.23 & 0.77 & 2.35 & 0.24 & 0.78 & 2.37 \\
\hline
\end{tabular}

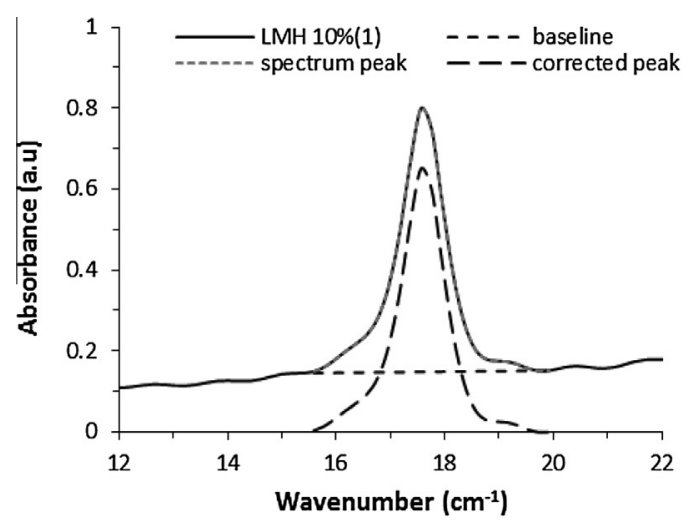

a

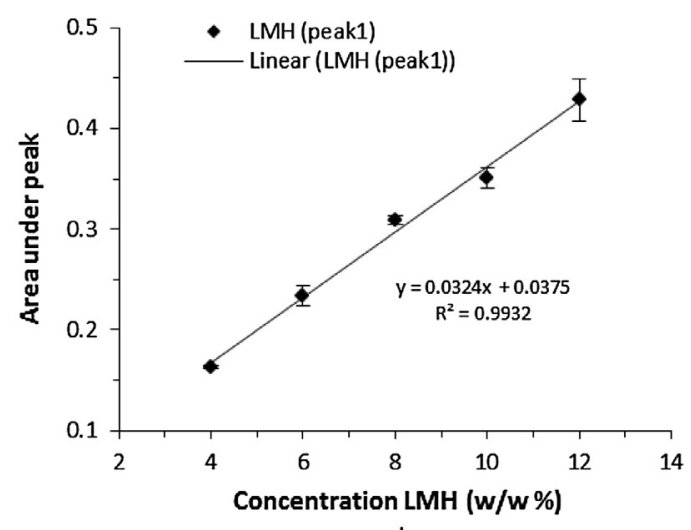

$\mathrm{b}$

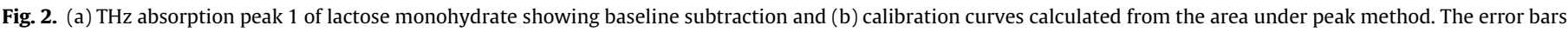
represent the standard deviation (SD) of the measurements $(n=9)$. 


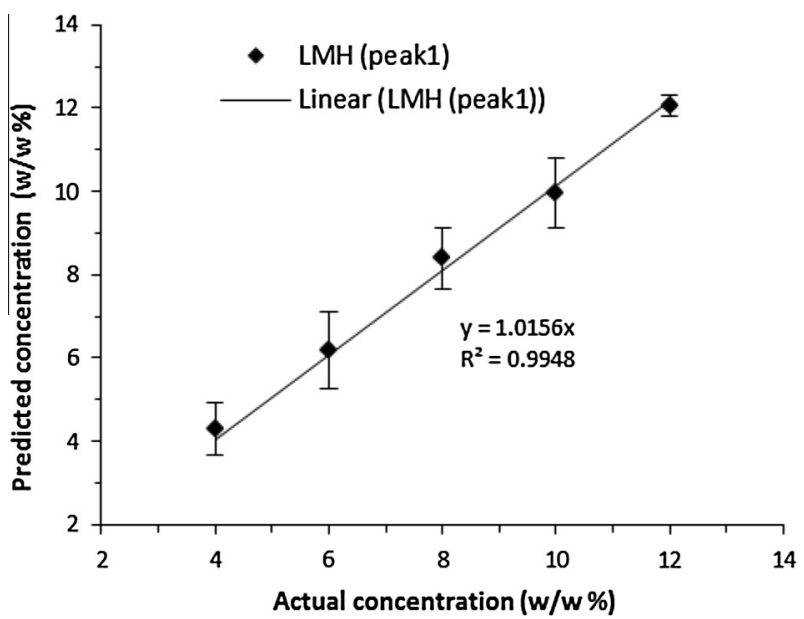

Fig. 3. Linear calibration model based on partial least square (PLS) applied to $\mathrm{THz}$ data of milled lactose monohydrate showing a good agreement between the predicted concentrations against calculated from this model. The error bars represent the standard deviation (SD) of the measurements $(n=9)$.

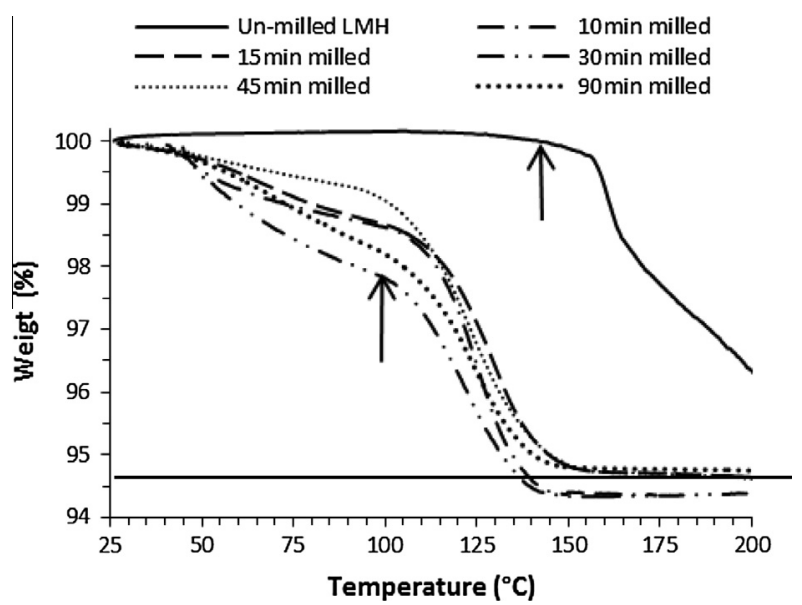

Fig. 4. TGA curves of un-milled and milled LMH (left), the onset temperature for desorption of crystallization water is indicated by arrow heads.

\section{Results and discussion}

\subsection{Thermogravimetric results}

The TGA thermogram of un-milled lactose monohydrate has shown that the weight of sample remained almost constant till $144{ }^{\circ} \mathrm{C}$ and afterward decreases sharply because of the desorption of the water of crystallization. (It should be noted that in all cases for the un-milled material, the thermogram did not reach a plateau.) In contrast, the onset for desorption of crystallization water is close to $110^{\circ} \mathrm{C}$ for the milled samples of lactose monohydrate. In the case of all the milled samples of $\mathrm{LMH}$, the thermogram reaches a plateau in the weight change after $150{ }^{\circ} \mathrm{C}$ (Fig. 4).

The factors that might be responsible for the $\sim 40{ }^{\circ} \mathrm{C}$ decrease in the onset temperature for desorption of the crystallization water in the milled materials (from $144^{\circ} \mathrm{C}$ before milling to $102{ }^{\circ} \mathrm{C}$ after 90 min milling) are (i) the development of new pathways for dehydration [27] in a structurally compromised crystalline phase, and (ii) a decrease in particle size [28].

The other principle difference between the TGA curves for the milled and un-milled materials is that the loss of the water of crystallization in the milled material is preceded by the release of a

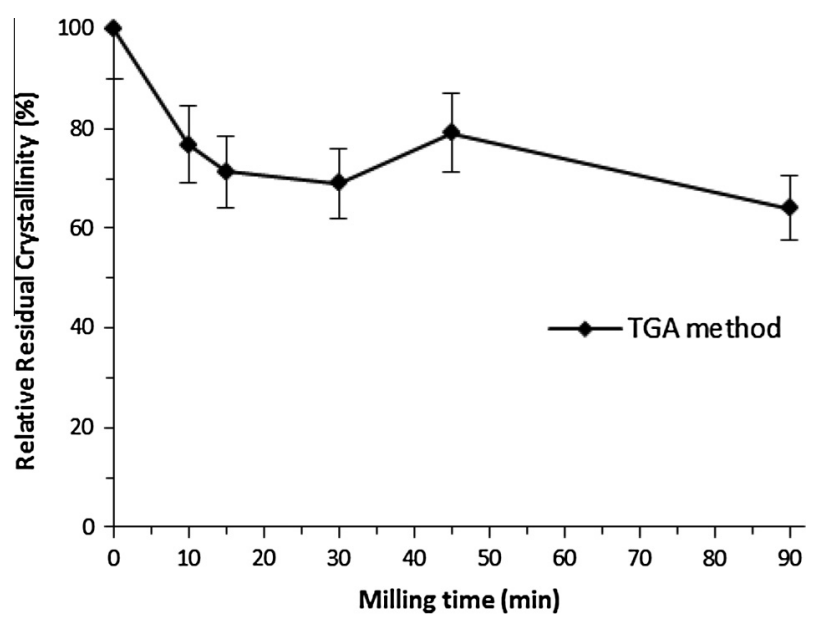

Fig. 5. Change in relative residual crystallinity (\%RRC) of lactose monohydrate with milling time as determined from TGA (SD $\pm 10 \%)$.

more significant portion of surface water than is otherwise observed in the un-milled material.

The percentage of non-crystalline water increases (from $0.4 \%$ in un-milled sample to $1.76 \%, 1.69 \%, 2.72 \%, 1.25 \%$ and $2.20 \%$ in samples milled for $10,15,30,45$ and 90 min respectively, while the amount of water of crystallization decreases with milling time. This is probably due to the desorption of water of crystallization that was released on milling, becoming physically admixed with the sample and responsible for the collapse of amorphous lactose as indicated in DSC results below.

The relative residual crystallinity (\%RRC) in the milled samples was calculated from the weight loss linked with desorption of the water of crystallization, having assumed that the starting material of crystalline LMH contains 5\% water of crystallization (as in the case for the un-milled material [6]). The amount of crystalline water decreases as the crystals are damaged with increasing the milling time.

TGA results (Fig. 5) have shown that the estimates for residual crystallinity decrease erratically with milling time, with the most significant decrease in crystallinity occurring over the first $10 \mathrm{~min}$. There is an approximate $\pm 10 \%$ variation in estimates of crystallinity in all milled samples of LMH (between 65\% and 75\%) meaning that it is not clear as to whether there is a progressive decrease in crystallinity as the milling time increases beyond $10 \mathrm{~min}$.

\subsection{Differential Scanning Calorimetry results}

The DSC curve of un-milled LMH (Fig. 6a) shows one endothermic peak with an onset temperature of $144^{\circ} \mathrm{C}$ corresponding to the release of water of crystallization (as evident from TGA results in Fig. 3), followed by one melting endotherm at $222{ }^{\circ} \mathrm{C}$ associated with the melting of $\alpha$-lactose (Fig. 6a). Such DSC results of LMH are in agreement with data reported by [29] but contrary to the observation of Gombas [30], who observed the splitting of desorption peak, followed by two melting endotherms corresponding to the alpha and beta forms of lactose.

On the other hand, the DSC curve of anhydrous lactose (Fig. 6a) has shown a melting endotherm at $238^{\circ} \mathrm{C}$ corresponding to the melting of $\beta$-lactose [31] and a tiny, broad endotherm at $140{ }^{\circ} \mathrm{C}$ corresponding to desorption of crystalline water, thereby indicating the presence of small quantity of LMH.

The DSC curves of milled samples of LMH (Fig. 6b) have shown that the desorption event consisted essentially of two peaks, first a broader peak between $116^{\circ} \mathrm{C}$ and $143^{\circ} \mathrm{C}$ and a second relatively 


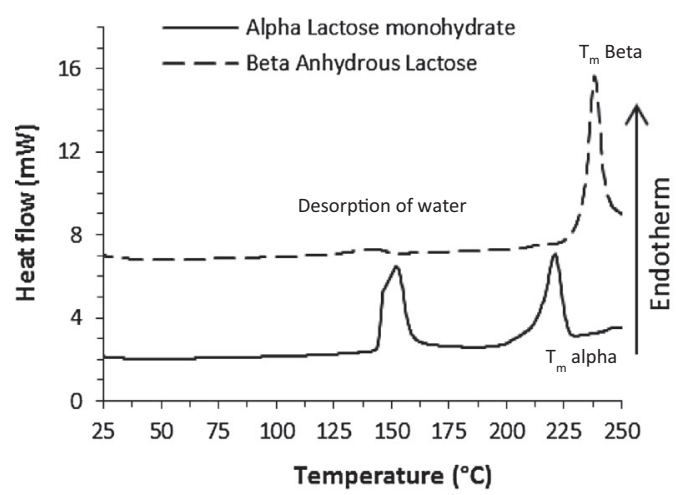

a

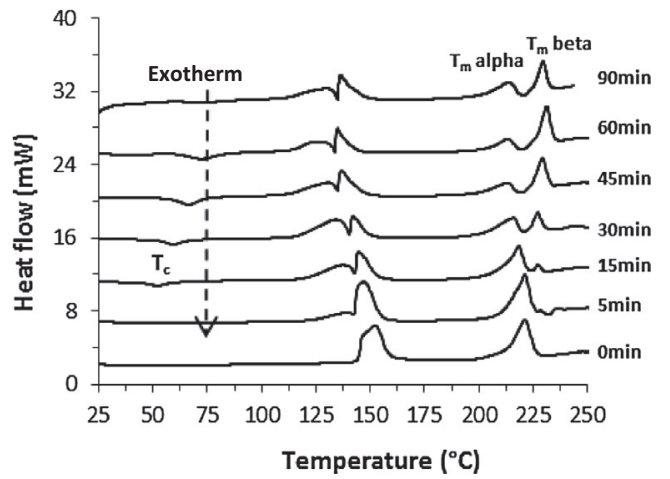

b

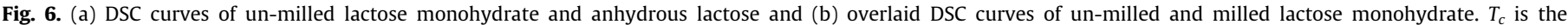
temperature of crystallization; $T_{m}$,alpha is the melting temperature of alpha anomer of lactose while $T_{m}$,beta is the melting temperature of beta anomer.

sharp peak between $131{ }^{\circ} \mathrm{C}$ and $157^{\circ} \mathrm{C}$. The melting event is also split into two peaks; the first from $210^{\circ} \mathrm{C}$ to $222^{\circ} \mathrm{C}$ and the second from $227^{\circ} \mathrm{C}$ to $236^{\circ} \mathrm{C}$ corresponding to the melting of $\alpha$ and $\beta$ lactose, respectively. Such behavior of milled LMH was previously reported by [27].

Another exothermic process in the DSC curves of milled samples after $15 \mathrm{~min}$ of milling was the de-vitrification of amorphous lactose which was observed between $52{ }^{\circ} \mathrm{C}$ and $73^{\circ} \mathrm{C}$. This event was previously reported at $\sim 170^{\circ} \mathrm{C}$ in fully amorphous (spray dried) or short milled lactose [28,30] but in collapsed amorphous (as produced by exposure of high relative humidity) it was reported to occur near $70^{\circ} \mathrm{C}$ [32]. Therefore it was inferred that the milling reduces the glass transition temperature probably due to the plasticization effect of water (released from hydrated crystals during milling). This inference is supported by the fact that the onset temperature for water desorption was decreased and percentage of un-bound water increased in milled samples (see TGA results). When this milled material was heated in the DSC it undergoes structural collapse at a reduced $T_{g}$ and gave a low temperature re-crystallization peak. The collapse of amorphous phase was complete as we did not observe the high temperature crystallization peak [32].

Mutarotation of lactose monohydrate is another expected change which is induced by heat and the presence of water during the DSC run $[33,34]$. The area of the de-vitrification peak and the ratio of the melting peak for beta lactose (as compared to alpha peak) increase as the milling time is increased up to 60 min (see Fig. 6b). This suggests that as the damage to the crystals increases, there is a greater proportion of amorphous lactose and a greater propensity to produce beta lactose. Therefore, it was inferred that the de-vitrified amorphous lactose forms $\beta$-lactose either at the de-vitrification temperature or it first re-crystallizes as the $\boldsymbol{\alpha}$-form [25], which subsequently undergoes mutarotation on heating to produce the beta form. This is in agreement with observations reported previously by $[28,30,35]$ that the greater the amorphous content, the greater is the structural collapse and the greater will be the $\beta$-anomer content in the lactose sample.

The relative residual crystalline content in milled samples (i.e. that proportion of the original starting material which has retained its native state and has not undergone a transformation of any kind to either another crystalline state, a partially damaged state, or a wholly amorphous state) was calculated from DSC data by following methods:

DSC Analysis method 1 is based on the approach taken by Phillips [36]. The assumptions are that (i) the second melting endotherm from the anhydrous $\beta$-form (Fig. 7, peak $\mathrm{D}^{\prime}$ ) is merely

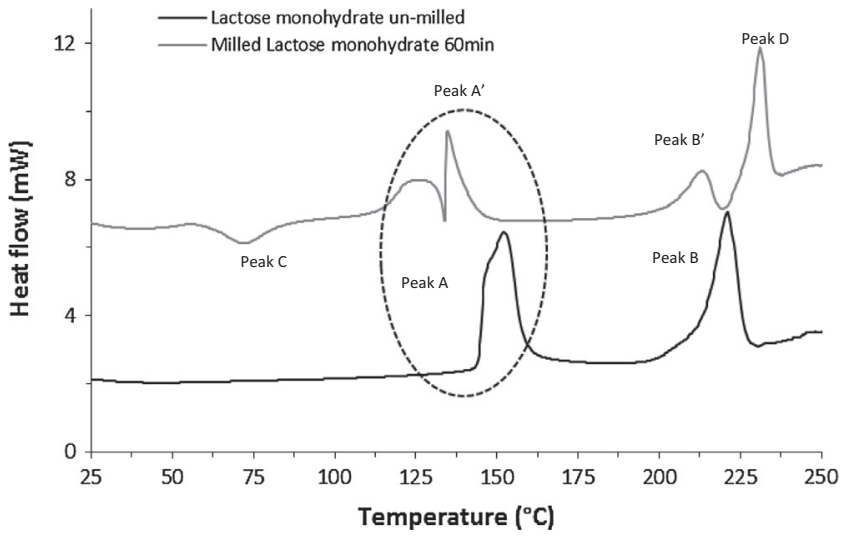

Fig. 7. DSC curves of un-milled lactose monohydrate (lower curve) and $60 \mathrm{~min}$ milled (upper curve). Peak A represents desorption, peak B is melting of alpha lactose, peak $\mathrm{C}$ is de-vitrification and peak $\mathrm{D}$ represents the melting of beta lactose.

an artifact of the DSC method, as it is generated from the de-vitrification of the amorphous phase (at temperature of $\sim 73{ }^{\circ} \mathrm{C}$ ) followed by the mutarotation of the alpha anomer and is therefore not used in the calculation, and (ii) the crystalline material that melts at temperature $\sim 217^{\circ} \mathrm{C}$ (for the un-milled) and $\sim 211^{\circ} \mathrm{C}$ (for the milled) (Fig. 7, peak $\mathrm{B}^{\prime}$ ) is that of the dehydrated $\alpha$-lactose monohydrate.

The method therefore takes the enthalpy of peak $\mathrm{B}^{\prime}$ and divides it by the melting enthalpy of the $100 \%$ anhydrous $\alpha$-lactose to provide the assessment of the remaining crystalline phase (Eq. (3)).

$X_{c}(\%)=\frac{\Delta H_{m, \alpha}}{\Delta H_{m, \alpha}(100 \% \text { crystalline })} \times 100$

where $X_{c}$ is the estimate for residual crystallinity, $\Delta H_{m, \alpha}$ is melting endotherm of alpha lactose $\left(\mathrm{J} \mathrm{g}^{-1}\right)$.

Given that there is a significant variation in the enthalpies of melting of alpha lactose as reported in literature (Table 2) it was not possible to select any one value that could satisfy the criteria of a reference value [37]. Therefore in our study, the molar heat of fusion for the un-milled lactose monohydrate of $\Delta H_{m}$ as $115.23 \mathrm{~J} \mathrm{~g}^{-1}$ was taken as our local reference value, and the residual crystallinity in milled samples represented as the percent relative residual crystallinity (\%RRC) of the starting material.

DSC Analysis method 2 is based on an assessment of the enthalpy of desorption of water of crystallization as a direct measure of the remaining crystalline content of LMH (as indicated by [30], and involves (Eq. (4)) the division of the desorption enthalpy 
Table 2

Literature values of enthalpy of melting $\left(\Delta H_{m}\right)$ of alpha lactose (anhydrous and monohydrate)

\begin{tabular}{lll}
\hline Reference & Material used & $\begin{array}{l}\Delta H_{m} \\
\left(\mathrm{~J} \mathrm{~g}^{-1}\right)\end{array}$ \\
\hline Drapier-Beche et al. [37] & $\begin{array}{l}\alpha \text {-lactose monohydrate (used as received } \\
\text { from Sigma, Germany) }\end{array}$ & 134 \\
Ticehurst et al. [21] & $\begin{array}{l}\alpha \text {-lactose monohydrate (four different } \\
\text { batches used as received from }\end{array}$ & 125 \\
& Lactochem, Netherland) & 101 \\
& $\begin{array}{l}\alpha \text {-lactose monohydrate (used as received } \\
\text { from Borculo Whey Product U.K.) }\end{array}$ & 169 \\
Dilworth et al. [6] & $\begin{array}{l}\text { Anhydrous } \alpha \text {-lactose (dehydration of } \\
\text { Caron et al. [20] }\end{array}$ & 151 \\
Drapier-Beche et al. [37] & $\begin{array}{l}\text { Anhydrous } \alpha \text {-lactose (dehydration of } \\
\text { lactose monohydrate from Sigma) }\end{array}$ & 122 \\
& & \\
\hline
\end{tabular}

of the milled material (Fig. 6, peak $\mathrm{A}^{\prime}$ ) by the desorption enthalpy of the $100 \%$ crystalline material (Fig. 6 peak A).

$X_{c}(\%)=\frac{\Delta H_{d h}}{\Delta H_{d h}(100 \% \text { crystalline })} \times 100$

where $\Delta H_{d h}$ is enthalpy of desorption of water of crystallization of milled lactose monohydrate samples and $\Delta H_{d h}$ of $100 \%$ crystalline was $121.8 \mathrm{~J} \mathrm{~g}^{-1}$, which is lower than already reported (i.e. $149 \mathrm{~J} \mathrm{~g}^{-1}$ ) by [38] and slightly higher than as reported $\left(110.3 \mathrm{~J} \mathrm{~g}^{-1}\right)$ by [21]. So again the concept of using a relative residual crystallinity term is necessary owing to the uncertainties in the values one might otherwise use to determine the actual starting material contents of alpha and beta lactose.

The assumption is that the molar enthalpy of desorption of the milled material is the same as that for the un-milled material. This may not be the case, given that the temperature of desorption of the milled crystalline material is lower than that for the intact materials. As a result the method is likely to under-estimate the amount of crystalline material remaining.

DSC Analysis method 3 is based on the approach taken from [39], whereby the amorphous content, $\boldsymbol{X}_{\boldsymbol{a}}$, is first estimated from the enthalpy of de-vitrification (Fig. 7, peak C) of the milled material divided by the enthalpy of de-vitrification of a $100 \%$ amorphous material, see Eq. (5).

$\boldsymbol{X}_{\boldsymbol{a}}(\%)=\frac{\Delta H_{c}}{\Delta H_{c}(100 \% \text { amorphous })} \times 100$

The $\Delta H_{c}$ value [ $105 \mathrm{~J} \mathrm{~g}^{-1}$ ] for $100 \%$ amorphous (spray dried) lactose was taken for calculations [39]. This is close to the melting enthalpy reported for anhydrous alpha lactose (i.e. $101 \mathrm{Jg}^{-1}$, by [21] and $115.2 \mathrm{~J} \mathrm{~g}^{-1}$ reported in this work). The crystalline content was then determined by applying Eq. (6).

$X_{c}(\%)=100-\boldsymbol{X}_{\boldsymbol{a}}(\%)$

The enthalpies of crystallization, desorption and melting for different milled samples of lactose monohydrate are given in Table 3 and the results of \%RRC in milled samples calculated by these three approaches have been summarized in Fig. 8.

Of the three methods, there appears to be a broad correlation between methods 2 and 3, which in turn have a similarity with the estimates of crystallinity from the TGA data. All three methods suggest that the crystallinity decreases by $\sim 20 \%$ at most across the 90 min milling time. Estimates from DSC Analysis method 1, are in contrast to methods 2 and 3 ; in that there is monotonous decrease in \%RRC with milling time up to 60 min where it reaches $\sim 25 \%$. Beyond this time point, i.e. on 90 min milling, there is an apparent reversal of some crystallinity (the \%RRC is $\sim 38 \%$ at this milling point).
Table 3

Values of enthalpies of crystallization $\left(\Delta H_{c}\right)$, dehydration $\left(\Delta H_{d h}\right)$ and melting $\left(\Delta H_{m}\right.$ alpha forms) of milled lactose which were used for the estimation of the \%RRC.

\begin{tabular}{clcl}
\hline $\begin{array}{l}\text { Milling time } \\
(\mathrm{min})\end{array}$ & $\begin{array}{l}\Delta H_{c} \\
\left(\mathrm{~J} \mathrm{~g}^{-1}\right)\end{array}$ & $\begin{array}{l}\Delta H_{d h}\left(\mathrm{~J} \mathrm{~g}^{-1}\right) \text { peaks } 1 \\
\text { and 2 }\end{array}$ & $\begin{array}{l}\Delta H_{m}\left(\mathrm{~J} \mathrm{~g}^{-1}\right) \text { alpha } \\
\text { form }\end{array}$ \\
\hline 0 & - & 121.76 & 115.23 \\
5 & - & 96.68 & 100.22 \\
15 & 13.63 & 77.12 & 67.17 \\
30 & 16.65 & 102.60 & 49.95 \\
45 & 26.59 & 75.76 & 35.26 \\
60 & 26.66 & 87.67 & 29.82 \\
90 & 7.71 & 97.36 & 44.45 \\
\hline
\end{tabular}

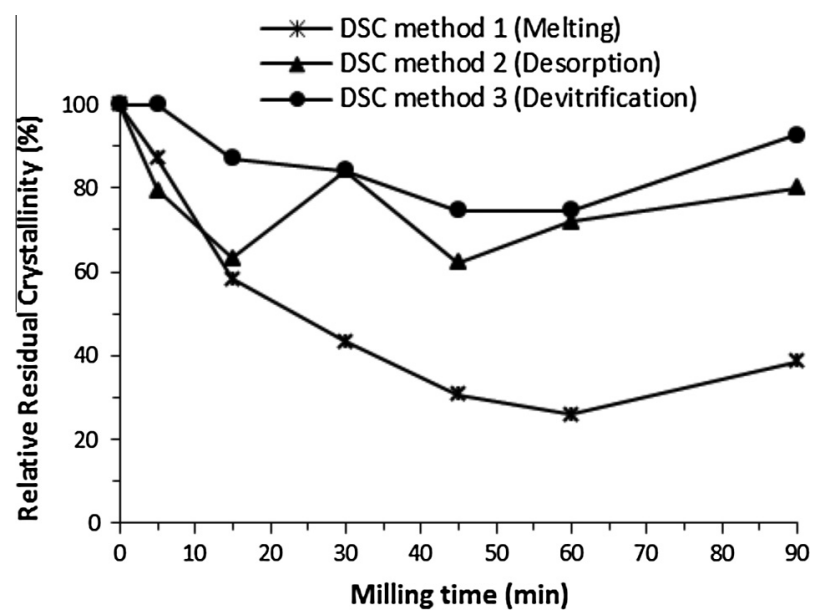

Fig. 8. Change in relative residual crystallinity (\%RRC) with milling time of LMH as determined from DSC using three different methods.

In DSC Analysis method 2, which is based on enthalpy of desorption of water of crystallization, there appears to be close agreement with method 1 in early time of milling ( $<15 \mathrm{~min})$. This might be because the basis of method 2 (desorbing of crystalline water) behaves similar to as the undamaged crystalline lactose monohydrate. Beyond that ( $>15$ min milling), there is fluctuation in estimates of \%RRC which lies within $70 \% \pm 10 \%$. This variation of $10 \%$ in estimate explains the apparent conformity or agreement between method 1 and 2 .

DSC Analysis method 3, which was based on de-vitrification peak of amorphous phase, shows the monotonic trend in the amount of \%RRC with milling time similar to method 1, but it produces higher estimates for the amount of \%RRC compared to method 1 (i.e. $\sim 75 \%$ at 60 min milling which is $\sim 25 \%$ in method 1). Also there is a re-conversion and increase in crystallinity ( $\sim 92 \%$ ) on 90 min milling similar to method 1, resulting from the instability of quite large volume of amorphous, in the presence of water which has been released from the damage to the hydrated crystals.

\subsection{Terahertz time domain spectroscopy results}

\subsubsection{THz spectrum of un-milled and milled lactose monohydrate}

The solid state $\mathrm{THz}$ spectrum of un-milled lactose monohydrate in transmission mode has shown four absorption peaks, as indicated by letters A-D (Fig. 9a) at $0.52,1.18,1.37$ and $1.80 \mathrm{THz}$ corresponding to $17.3,39.2,45.2$ and $60.1 \mathrm{~cm}^{-1}$ and another peak near $82 \mathrm{~cm}^{-1}$ which is noisy in samples with higher concentrations of LMH (Fig. 9b). The first and third peaks (at 0.52 and $1.37 \mathrm{THz}$ Peak ' $A$ ' and 'B' respectively in Fig. 9a) are considered as the signatures of LMH [40] and these peaks are assigned to the intermolecular vibrations of hydrogen bonded crystalline structure [41] or 


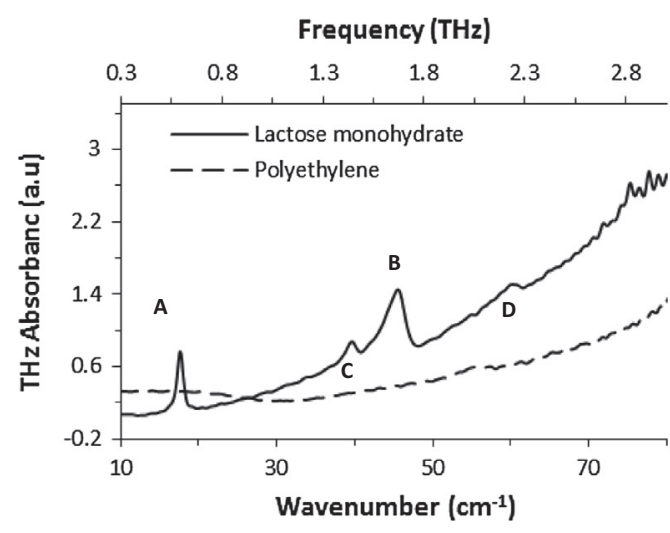

a

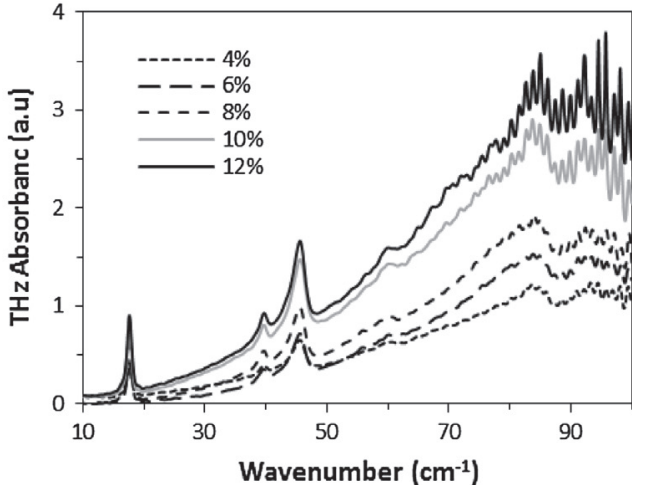

b

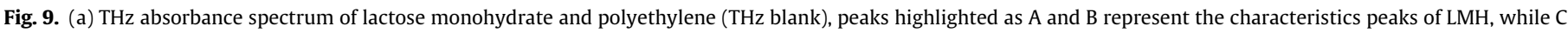
and D represent the beta lactose content in lactose monohydrate as impurity and (b) overlaid THz spectra of different concentrations of un-milled LMH.

more specifically the peak at $\sim 0.52 \mathrm{THz}$ to a hindered rotational mode of a particular axis of its crystals [42]. The peaks at 1.18 and $1.80 \mathrm{THz}$, Peak ' $\mathrm{C}$ ' and 'D' respectively in Fig. 9a are because of beta lactose present in the samples of lactose monohydrate. This is confirmed by the comparison of $\mathrm{THz}$ spectrum of $\alpha$-lactose monohydrate with that of anhydrous beta lactose (commercial source) as shown as bottom and top curves respectively in Fig. 9a.

Another feature of the $\mathrm{THz}$ spectra of un-milled $\mathrm{LMH}$ was the manifestation of Mie scattering. This phenomenon, of increased absorbance toward higher frequencies, is a consequence of the mean particle size of sample reaches the wavelength of the incidence radiation [43]. This scattering was especially prominent in the un-milled $\mathrm{LMH}$ due to the presence of large particles $(\sim 150 \mu \mathrm{m})$ and it increases with increasing concentration of lactose in the sample pellets (Fig. 9b).

The THz spectra of milled LMH (shown in Fig. 10) are very similar to that of un-milled LMH in terms of the position of absorption peaks. However, the intensities of the major peaks ( $A$ and $B$ of Fig. 9a) decrease with milling time, indicating a progressive damage to the crystalline structure. The $2^{\text {nd }}$ peak (near $45 \mathrm{~cm}^{-1}$ ) becomes more prominent in the short milled samples ( $<10 \mathrm{~min}$ ) but diminishes on further milling $(>10 \mathrm{~min}$ ). The spectra of the long milled (45 min and $60 \mathrm{~min}$ ) samples show only two peaks with a diminished shoulder of the $2^{\text {nd }}$ peak and an almost flat and featureless spectrum toward longer wavenumbers [14], which is rather typical of an amorphous material. Beyond this time point

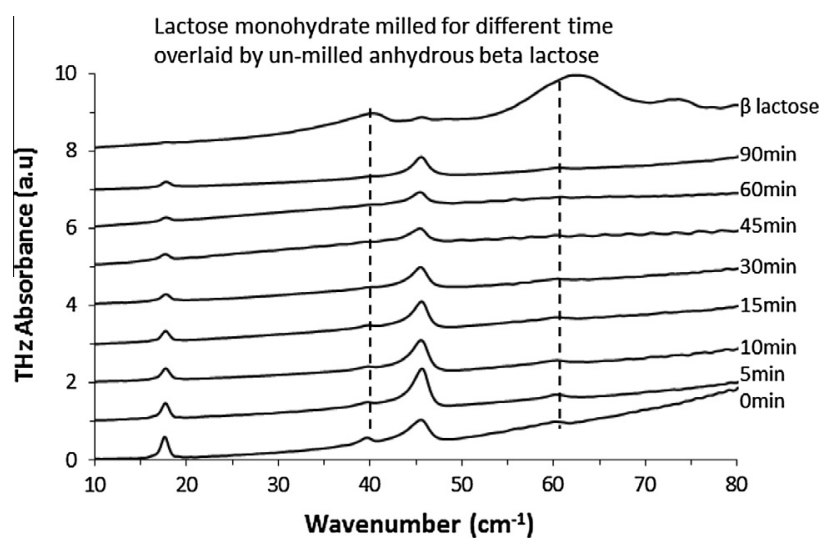

Fig. 10. THz spectra of milled lactose monohydrate for different times, overlaid by $\mathrm{THz}$ spectrum of anhydrous beta lactose for comparison. The dotted lines represent the peaks of beta lactose that is present in un-milled alpha lactose monohydrate and diminish in the milled samples. (i.e. 90 min milling) the spectral peaks, which diminished before, again become prominent, which suggests a de-vitrification of the material. At this time point, a characteristic peak $\left(\sim 94 \mathrm{~cm}^{-1}\right)$ of anhydrous $\alpha$-lactose [44] was present, which may have been produced by desorption of LMH or by de-vitrification of amorphous phase.

It is important to note that the spectral peaks of $\beta$-lactose (i.e. on $\sim 39$ and $\sim 60 \mathrm{~cm}^{-1}$ ) diminish with milling (Fig. 10), so that the milled samples ( $>30 \mathrm{~min}$ ) contain only the traces of beta lactose. Therefore, it may be concluded that the milling does not cause any promising mutarotation i.e. conversion of $\alpha$-lactose to beta lactose [45] which is contrary to the early reports that milling caused $\sim 20 \%$ mutarotation [46].

\subsection{2. $\mathrm{THz}$ analysis: method 1 (area under the peak) and method 2} (partial least square)

Both the area under the peak data and the PLS data show a monotonic decrease in crystallinity with milling time. The most intensive/sharp reduction occurs at the beginning of milling where the \%RRC reaches $\sim 25 \%$ after 30 min of milling. Beyond this time point there is relatively slow loss of further $5-15 \%$ crystallinity (as seen by both methods of analysis) during the next $30 \mathrm{~min}$ (relative \%RRC is $\sim 15 \%$ in the 60 min milled sample (see Fig. 11). On further milling, the PLS data show an apparent $(\sim 8 \%)$ recovery of the crystalline phase (presumably due to a partial de-vitrification of

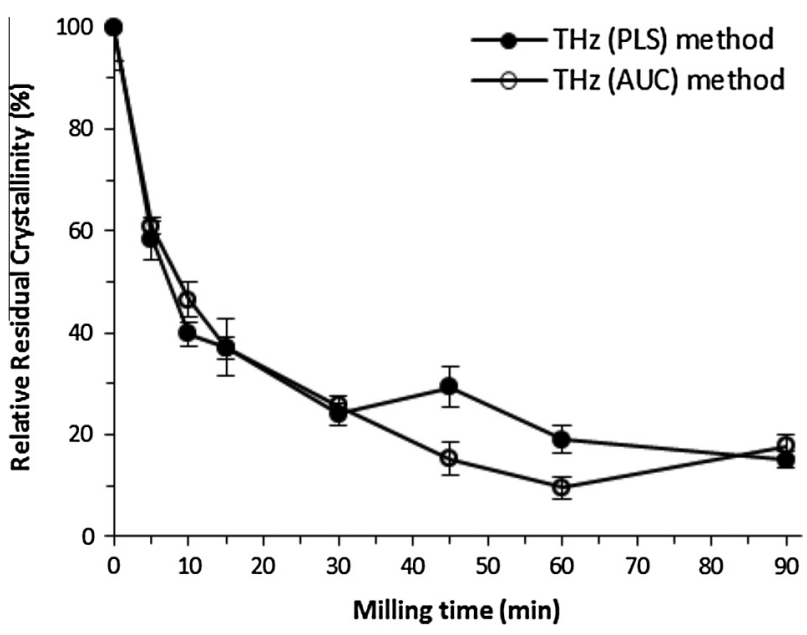

Fig. 11. Comparison of relative residual crystallinity (\%RRC) on milling as calculated by area under peak method and PLS methods applied on $\mathrm{THz}$ data. The error bars represent the standard deviation (SD) of the measurements $(n=9)$. 
the amorphous phase) to yield a crystalline content of $\sim 18 \%$ at $90 \mathrm{~min}$ of milling. However, this suggestion does not appear to be substantiated by the AUC method which shows a broadly monotonic decrease across the whole time frame of the milling process.

The THz method of crystalline quantification has indicated that the crystalline lattice was damaged rapidly in the early minutes of milling, while on long time milling it does not change much probably due to effect of the water released during milling [28]. The amount of residual crystalline content of lactose monohydrate present in milled sample is still sufficient to produce the structural modes presented as the reduced peaks in the $\mathrm{THz}$ spectrum. Generally, both $\mathrm{THz}$ methods for data analysis give very similar results (see Fig. 11). The AUC method appears more scattered and shows that the crystallinity continues to decrease across the entire milling time, whereas the PLS method seems to reveal that there is a partial recovery at long milling time i.e. $>60 \mathrm{~min}$ (as was observed in the DSC method). One of the reasons the predicted results from the PLS model were slightly different to the AUC results was that the AUC method is less sensitive to the peak shape.

\subsection{3. $\mathrm{THz}$ baseline characterization}

It would appear from Fig. 10 that changes to the baseline on milling are somewhat complex, in that the baseline first decreases in the early stages of milling, and then increase toward the later stages of milling. In order to examine more closely this behavior, a region of the baseline at frequencies slightly higher than peak 2 , i.e. $50-55 \mathrm{~cm}^{-1}$, was taken for analysis, by fitting a simple linear function to the data (Fig. 12).

Interpolated values for the absorbance at $50 \mathrm{~cm}^{-1}$ and the gradient of the line between 50 and $55 \mathrm{~cm}^{-1}$ were then plotted in Fig. 13 in order to demonstrate the competition between the impact of the reduction in particle size and the formation of the amorphous phase have on the characteristics of the base line.

In the early stages of milling (up to $10 \mathrm{~min}$ ) both the gradient and offset of the baseline decrease, presumably because the predominant effect is that of reduced light scattering from the comminuted particles. On milling beyond $10 \mathrm{~min}$ the gradient of the baseline continues to decrease (as the particles get ever smaller). However, the change in the baseline offset reverses beyond 10 min of milling and starts to increase again, presumably because the modes related to the vibrational density of states (VDOS), a phenomenon indicative of disordered system [47,48], now begin to dominate the baseline characteristics.

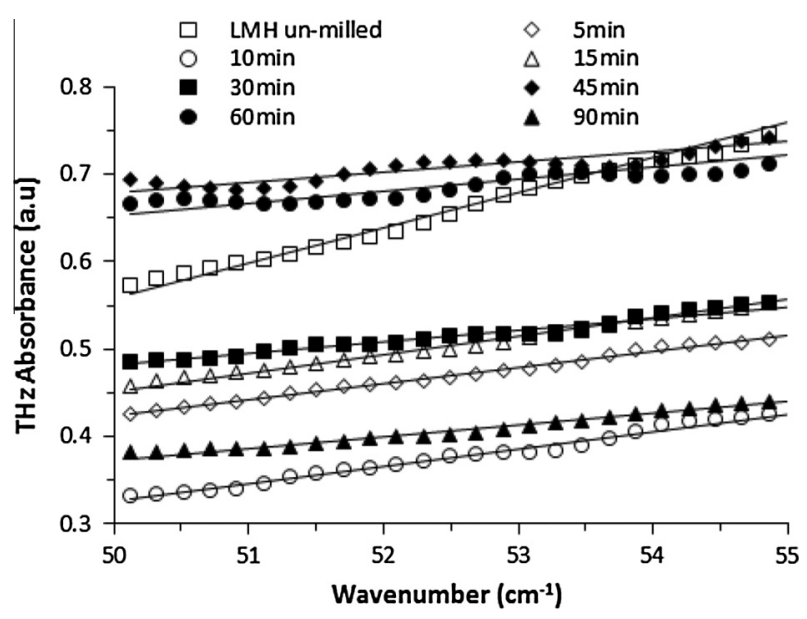

Fig. 12. A region of $\mathrm{THz}$ spectra (from 50 to $55 \mathrm{~cm}^{-1}$ ) of milled lactose monohydrate showing the baseline effects as change in gradients and shift of the offset.

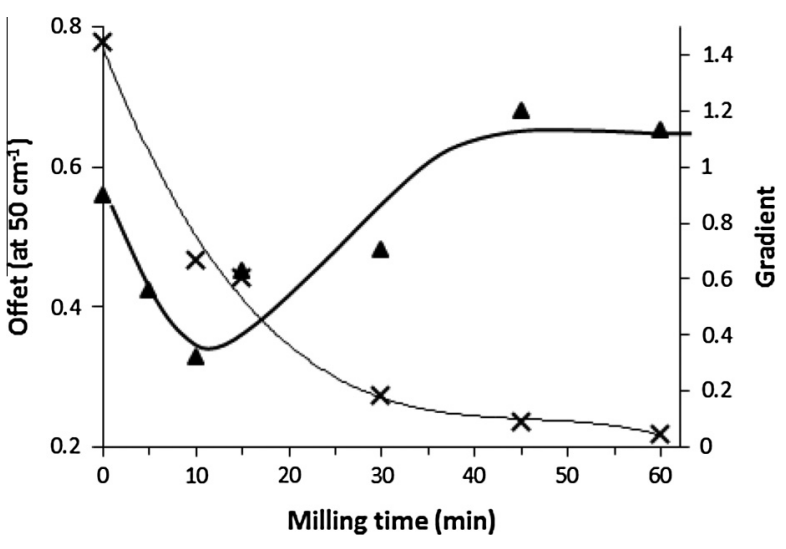

Fig. 13. Plot of gradient and offset of $\mathrm{THz}$ spectra at higher frequencies for unmilled and different milled samples of lactose monohydrate.

It is interesting to compare the trending in the reduction of the crystalline content (from the $\mathrm{THz}$ analysis of peak 1, Fig. 11) with what is observed in the baseline characteristics. Given that the baseline is strongly impacted by particle size effects during the early stages of milling then it was considered more appropriate to restrict this comparison to that stage of the milling cycle in which particle size has minimal impact on the characteristics of the baseline so that the impact of amorphization may dominate the baseline characteristics (i.e. the period between $15 \mathrm{~min}$ and 90 min of milling). During this time period, there is approximate halving of the crystalline content from $~ 40 \%$ to $20 \%$ which appears (notwithstanding the scatter in the data) to be mirrored by an approximate doubling of the offset (from $\sim 0.33$ to $\sim 0.66$ ). However, given the scatter in the baseline data it is unlikely that this behavior may be used for a quantitative estimation of the amorphous content.

\section{Discussion}

It is expected that milled samples will contain a number of crystalline, partially damaged (i.e. compromised crystalline material) and fully amorphous phases, as a consequence of the high energy collisions of the particles. Results from various techniques and methods of data analysis provide a range of estimates for the decrease in crystallinity, with all techniques generally showing similar behavior, i.e. a generalized decrease in the proportion of the crystalline part with milling time. This outcome may be considered somewhat inevitable given that each approach is based on the analysis of a different facet of the collection of milled particles. The discussion will center of an exploration of these differences between the different approaches.

\subsection{Comparison of DSC and TGA results}

One feature of the estimates for \%RRC, as determined by TGA, is that they are generally much higher than estimates from DSC method 1, but quite similar to the results obtained by DSC method 2 (Fig. 14). The disparity between TGA and DSC method 2 compared with DSC method 1 , was probably due to the fact that the estimation of crystallinity was based on the same physical approach, i.e. desorption of the crystallization water. In the case of TGA, the assessment was based on the weight loss linked to the release of water of crystallization; and in the case of DSC method 2, the assessment was based on the desorption endotherm. Therefore, while the estimate of crystallinity may actually represent that part of the (crystalline) material which is largely unchanged during milling process, it may also include that part which 
is partially damaged during milling but still retains some form of entrapped water (which may in fact be considered as some form of water of crystallization). This would lead to a higher estimate of crystallinity in the milled material than a method which is based on the assessment of the melting endotherm of lactose mono-hydrate (i.e. DSC method 1). One should also remember that the percentage loss of crystallinity (as determined by TGA) is based on the assumption that the starting material comprises only alpha lactose monohydrate, with a water content of $5 \%$. Inevitably this is added to the estimate of the residual crystalline content.

Another feature of the estimates for \%RRC from TGA and from DSC method 2 is the undulation in the data over time, which could result from the variation in the characteristics of the material taken as a sample from the ball mill. It is possible that a material in which crystals are weakened on milling, may allow for water to leach out before analysis, and this would reflect less \%RRC than the sample in which water of crystallization is relatively stable. Such effects would be exacerbated from a lack of uniformity across the milled material.

A comparison of DSC methods 2 and 3 reveals that the assessment of crystallinity agrees with each other. However, this is likely to be a coincidence as they are based on very different and indirect methodologies. As stated previously, both methods give a higher assessment of crystallinity than DSC method 1 . The biggest discrepancy is for DSC method 3 because of its reliance on the process of de-vitrification and the presumption that this process is completed within the time frame of the DSC analysis. However, at the scan rate of $20^{\circ} \mathrm{C} \mathrm{min}^{-1}$ there may be insufficient time to allow for complete de-vitrification. Moreover, this process would be impacted by the amount of water in each sample, therefore introducing a further degree of variability in the assessment of crystallinity. Also there is loss of sensitivity at early time points where the amorphous content is too low to observe the de-vitrification peak. The minimum sensitivity is $\sim 13 \%$ of amorphous in order to detect and make a reliable estimation of \%RRC by this method; so it follows that the estimates for \%RRC are likely to be too high.

Based on the discussion above we might pre-suppose that the broad agreement between three of our methods (i.e. TGA, DSC method 2 and DSC method 3) implies that these estimates for the \%RRC provide a more realistic assessment of the damage induced by milling. However, it is recognized that at least two of these methods (i.e. TGA and DSC method 2) are likely to include proportions of material that have been structurally compromised in some way. In the case of DSC method 1, the assessment of \%RRC is based on the melting endotherm of $\alpha$-lactose monohydrate. Any amorphous form which devitrifies on heating within the DSC experiment is presumed to crystallise out exclusively as the beta form (and not the alpha form as discussed in Section 3.2) and therefore does not contribute to the melting endotherm of $\alpha$-lactose monohydrate.

\subsection{Comparison of DSC (method 1 ) and $\mathrm{THz}$ results}

The assumption that the de-vitrification of a proportion of the amorphous form to the beta form, on heating within the DSC experiment, is borne out by the $\mathrm{THz}$ data which demonstrate the absence of any increase in the beta form, post milling. Therefore the calculation (method 1) of residual crystalline content in milled samples may be based entirely on the melting enthalpy of $\alpha$ anomer.

Out of all methods studied, it was observed that the estimates for \%RRC by DSC method 1 and from both THz methods (i.e. AUC and PLS) were the closest to one another, in that the rate of decrease in crystallinity followed a similar trend (Fig. 14). However, the DSC estimates were generally higher than that from the $\mathrm{THz}$ analysis. This might suggest that the aforementioned exclusive de-vitrification of the amorphous form into the beta form, may not be strictly true and that de-vitrification may also re-introduce a proportion of the $\alpha$-form.

The impact of this transition on the estimates for \%RRC may be observed also in Fig. 15 (a plot of the DSC method 1 estimate for \%RRC and average estimates of \%RRC from the two THz methods), in which a proportionality constant of 1.43 suggests that DSC over estimates the relative residual crystallinity by a factor of $\sim 40 \%$.

Another feature of both the DSC method 1 and $\mathrm{THz}$ method is that the monotonic loss in first 60 min of milling is followed by an apparent increase in the crystallinity following 90 min milling. Given that this recovery of the crystalline phase was revealed in both these methods, it was therefore presumed to be a real effect. This effect is likely to be a consequence of the significant proportion of amorphous phase that has been produced, which has propensity for de-vitrification between the end of milling and the time point for analysis.

It is clear from the observations at extended milling times (>60 min) that the energy introduced by milling is insufficient to convert the material to a $100 \%$ amorphous state. During milling the mechanical properties of lactose are changed from strong and brittle (un-milled crystals) to elastic and ductile (amorphous

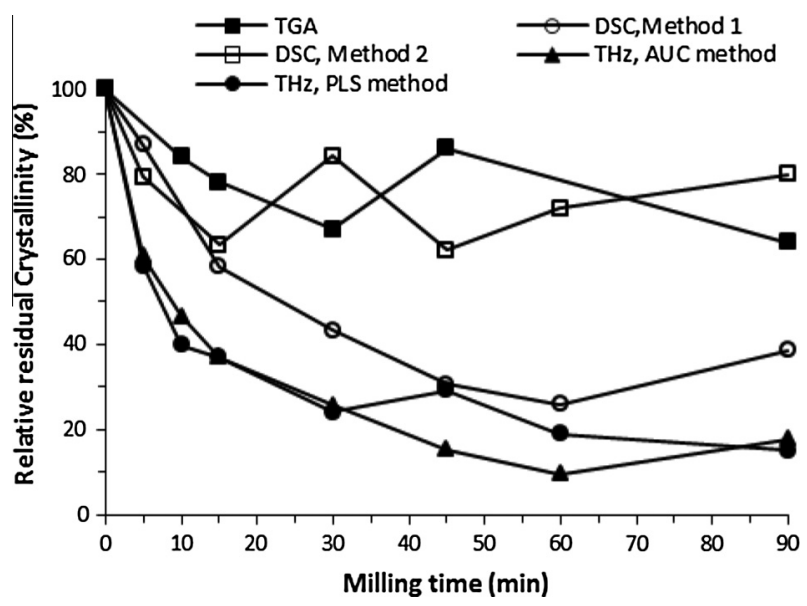

Fig. 14. Comparison of relative residual crystallinity (\%RRC) of lactose monohydrate as calculated by DSC (method 1 and 2), TGA and THz methods (AUC \& PLS).

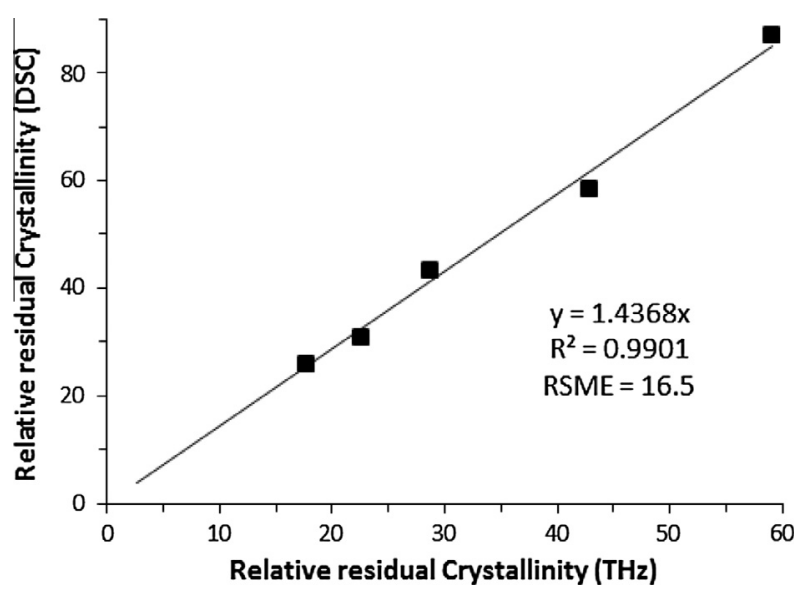

Fig. 15. Comparison of estimates of crystallinity of lactose monohydrate with milling time as measured by DSC method- 1 and THz methods. The line of best fit has been forced through zero in order to generate an estimate for the constant of proportionality. 
state). Once this has occurred to a certain degree, then the mechanical force is no longer transferred to the crystalline material (rather it is dissipated by the amorphous part) and therefore there is insufficient energy for further destruction of residual crystalline part of the material. Therefore the crystallinity of material does not reduce further, after $60 \mathrm{~min}$ milling time. However, if the experimental conditions would be changed (for example for higher frequency, i.e. energy) then the amount of amorphous material will inevitably increase.

In summary, the $\mathrm{THz}$ estimates of \%RRC are more promising and consistent as this technique is non-invasive and directly measures the crystallinity by probing the lattice of solid material. In contrast, the thermo-analytical methods are indirect methods based on the assessment of transitions between different physical states of the material, which are dependent on the temperature rate and values that can be applied for the specific enthalpy of melting of each crystalline state.

\section{Conclusion}

The commercially available $\alpha$-lactose monohydrate used for this study inevitably contains some percentage of beta lactose (which evident in the $\mathrm{THz}$ results but not in the DSC results) and therefore all values for residual crystallinity have been given in terms of a relative residual crystallinity (\%RRC) on milling with respect to the alpha anomer.

The results have shown that both DSC method 1 and the $\mathrm{THz}$ method yield almost similar results in terms of the assessment of crystallinity in the milled hydrated material, with both techniques indicating that there is a limit of $\sim 80 \%$ loss of the starting crystalline content of alpha lactose monohydrate, which occurs after 60 min, while TGA appears to show higher crystallinities because the evaluation was based on the weight of crystallization water without any consideration of the structural damage to the crystal nor the presence of an amorphous phase. Therefore it can be concluded that DSC methods may be used in this context but it requires more steps in the calculation (to account for the induced de-vitrification and mutarotation of LMH during analysis by DSC) which therefore introduces a greater number of assumptions and sources of error, while $\mathrm{THz}$ measures the material in its native state and is based on simple absorption spectra, requiring fewer assumptions and therefore standard computational techniques are satisfactory. In addition, a principle advantage of $\mathrm{THz}$ over DSC might be that the technique could be adapted for on-line measurements and process control.

\section{Acknowledgment}

Authors would like to thank Nicholas Pedge, Associate Principal Scientist, AstraZeneca Macclesfield, UK for his chemometric analysis of the THz data using Matlab. Amjad Hussain acknowledges the University of the Punjab, Lahore, Pakistan for PhD Scholarship.

\section{References}

[1] V. Chikhalia, R. Forbes, R. Storey, M. Ticehurst, The effect of crystal morphology and mill type on milling induced crystal disorder, Eur. J. Pharm. Sci. 27 (1) (2006) 19-26.

[2] E. Dudognon, J.F. Willart, V. Caron, F. Capet, T. Larsson, M. Descamps, Formation of budesonide/ $\alpha$-lactose glass solutions by ball-milling, Solid State Commun. 138 (2) (2006) 68-71.

[3] M.L. Branham, T. Moyo, T. Govender, Preparation and solid-state characterization of ball milled saquinavir mesylate for solubility enhancement, Eur. J. Pharm. Biopharm. 80 (1) (2012) 194-202.

[4] J. Zhang, S. Ebbens, X. Chen, Z. Jin, S. Luk, C. Madden, et al., Determination of the surface free energy of crystalline and amorphous lactose by atomic force microscopy adhesion measurement, Pharm. Res. 23 (2) (2006) 401-407.
[5] P.M. Young, H. Chiou, T. Tee, D. Traini, H.-K. Chan, F. Thielmann, et al., The use of organic vapor sorption to determine low levels of amorphous content in processed pharmaceutical powders, Drug Dev. Ind. Pharm. 33 (1) (2007) 91-97.

[6] S.E. Dilworth, G. Buckton, S. Gaisford, R. Ramos, Approaches to determine the enthalpy of crystallisation, and amorphous content, of lactose from isothermal calorimetric data, Int. J. Pharm. 284 (1-2) (2004) 83-94.

[7] B. Shah, V.K. Kakumanu, A.K. Bansal, Analytical techniques for quantification of amorphous/crystalline phases in pharmaceutical solids, J. Pharm. Sci. 95 (8) (2006) 1641-1665.

[8] G. Buckton, A. Choularton, A.E. Beezer, S.M. Chatham, The effect of the comminution technique on the surface energy of a powder, Int. J. Pharm. 47 (1-3) (1988) 121-128.

[9] S.J. Bai, M. Rani, R. Suryanarayanan, J.F. Carpenter, R. Nayar, M.C. Manning, Quantification of glycine crystallinity by near-infrared (NIR) spectroscopy, J. Pharm. Sci. 93 (10) (2004) 2439-2447.

[10] G. Buckton, P. Darcy, Assessment of disorder in crystalline powders-a review of analytical techniques and their application, Int. J. Pharm. 179 (2) (1999) $141-158$.

[11] G. Buckton, E. Yonemochi, J. Hammond, A. Moffat, The use of near infra-red spectroscopy to detect changes in the form of amorphous and crystalline lactose, Int. J. Pharm. 168 (2) (1998) 231-241.

[12] O.C. Chidavaenzi, G. Buckton, F. Koosha, R. Pathak, The use of thermal techniques to assess the impact of feed concentration on the amorphous content and polymorphic forms present in spray dried lactose, Int. J. Pharm. 159 (1) (1997) 67-74.

13] C.J. Strachan, T. Rades, D.A. Newnham, K.C. Gordon, M. Pepper, P.F. Taday, Using terahertz pulsed spectroscopy to study crystallinity of pharmaceutical materials, Chem. Phys. Lett. 390 (1) (2004) 20-24.

[14] C.J. Strachan, P.F. Taday, D.A. Newnham, K.C. Gordon, J.A. Zeitler, M. Pepper et al., Using terahertz pulsed spectroscopy to quantify pharmaceutical polymorphism and crystallinity, J. Pharm. Sci. 94 (4) (2005) 837-846.

[15] H.B. Liu, Y. Chen, X.C. Zhang, Characterization of anhydrous and hydrated pharmaceutical materials with $\mathrm{THz}$ time-domain spectroscopy, J. Pharm. Sci. 96 (4) (2007) 927-934.

[16] J.A. Zeitler, K. Kogermann, J. Rantanen, T. Rades, P.F. Taday, M. Pepper, et al., Drug hydrate systems and dehydration processes studied by terahertz pulsed spectroscopy, Int. J. Pharm. 334 (1) (2007) 78-84.

[17] J. Darkwah, G. Smith, I. Ermolina, M. Mueller-Holtz, A THz spectroscopy method for quantifying the degree of crystallinity in freeze-dried gelatin amino acid mixtures: an application for the development of rapidly disintegrating tablets, Int. J. Pharm. 455 (1) (2013) 357-364.

[18] I. Ermolina, J. Darkwah, G. Smith, Characterisation of crystalline-amorphous blends of sucrose with terahertz-pulsed spectroscopy: the development of a prediction technique for estimating the degree of crystallinity with partial least squares regression, AAPS PharmSciTech. (2013) 1-8.

[19] G. Pilcer, K. Amighi, Formulation strategy and use of excipients in pulmonary drug delivery, Int. J. Pharm. 392 (1-2) (2010) 1-19.

[20] V. Caron, J.F. Willart, R. Lefort, P. Derollez, F. Danède, M. Descamps, Solid state amorphization kinetic of alpha lactose upon mechanical milling, Carbohydr Res. 346 (2011) 2622-2628.

[21] M. Ticehurst, P. York, R. Rowe, S. Dwivedi, Characterisation of the surface properties of $\alpha$-lactose monohydrate with inverse gas chromatography, used to detect batch variation, Int. J. Pharm. 141 (1) (1996) 93-99.

[22] C.C. Kwan, Y.Q. Chen, Y.L. Ding, D.G. Papadopoulos, A.C. Bentham, M. Ghadiri, Development of a novel approach towards predicting the milling behaviour of pharmaceutical powders, Eur. J. Pharm. Sci. 23 (4-5) (2004) 327-336.

[23] M. Hurtta, I. Pitkänen, J. Knuutinen, Melting behaviour of D-sucrose, D-glucose and D-fructose, Carbohydr. Res. 339 (13) (2004) 2267-2273.

[24] L. Nørgaard, M.T. Hahn, L.B. Knudsen, I.A. Farhat, S.B. Engelsen, Multivariate near-infrared and Raman spectroscopic quantifications of the crystallinity of lactose in whey permeate powder, Int. Dairy J. 15 (12) (2005) 12611270.

[25] A.I. McIntosh, B. Yang, S.M. Goldup, M. Watkinson, R.S. Donnan, Crystallization of amorphous lactose at high humidity studied by terahertz time domain spectroscopy, Chem. Phys. Lett. 558 (2013) 104-108.

[26] J. Sibik, M.J. Sargent, M. Franklin, J.A. Zeitler, Crystallization and phase changes in paracetamol from the amorphous solid to the liquid phase, Mol. Pharm. 11 (4) (2014) 1326-1334.

[27] S. Garnier, S. Petit, F. Mallet, M.N. Petit, D. Lemarchand, S. Coste, et al., Influence of ageing, grinding and preheating on the thermal behaviour of $\alpha$ lactose monohydrate, Int. J. Pharm. 361 (1-2) (2008) 131-140.

[28] M.H. Shariare, M. de Matas, P. York, O. Shao, The impact of material attributes and process parameters on the micronisation of lactose monohydrate, Int. J. Pharm. 408 (1-2) (2011) 58-66.

29] V. Moolchandani, L.L. Augsburger, A. Gupta, M. Khan, J. Langridge, S.W. Hoag Characterization and selection of suitable grades of lactose as functional fillers for capsule filling: part 1, Drug Dev. Ind. Pharm. (2014) 1-12.

[30] Á. GombÁs, P. Szabó-Révész, M. Kata, G. Regdon, I. Erős, Quantitative determination of crystallinity of $\alpha$-lactose monohydrate by DSC, J. Therm. Anal. Calorim. 68 (2) (2002) 503-510.

[31] Y. Listiohadi, J.A. Hourigan, R.W. Sleigh, R.J. Steele, Thermal analysis of amorphous lactose and alpha-lactose monohydrate, Dairy Sci. Technol. 89 (1) (2009) 43-67.

[32] P. Darcy, G. Buckton, The influence of heating/drying on the crystallisation of amorphous lactose after structural collapse, Int. J. Pharm. 158 (2) (1997) 157 164. 
[33] S. Garnier, S. Petit, G. Coquerel, Dehydration mechanism and crystallisation behaviour of lactose, J. Therm. Anal. Calorim. 68 (2) (2002) 489-502.

[34] S. Garnier, S. Petit, G. Coquerel, Influence of supersaturation and structurally related additives on the crystal growth of $\alpha$-lactose monohydrate, J. Cryst. Growth 234 (1) (2002) 207-219.

[35] G. Buckton, Characterisation of small changes in the physical properties of powders of significance for dry powder inhaler formulations, Adv. Drug Deliver. Rev. 26 (1) (1997) 17-27.

[36] E.M. Phillips, An approach to estimate the amorphous content of pharmaceutical powders using calorimetry with no calibration standards, Int. J. Pharm. 149 (2) (1997) 267-271.

[37] N. Drapier-Beche, J. Fanni, M. Parmentier, Physical and chemical properties of molecular compounds of lactose, J. Dairy Sci. 82 (12) (1999) 2558-2563.

[38] R.L. Blaine, Determination of Polymer Crystallinity by DSC, TA123, TA Instrument Publication, New Castle, DE, 2010, pp. 1-3.

[39] V.-P. Lehto, M. Tenho, K. Vähä-Heikkilä, P. Harjunen, M. Päällysaho, J. Välisaari, et al., The comparison of seven different methods to quantify the amorphous content of spray dried lactose, Powder Technol. 167 (2) (2006) 85-93.

[40] E. Brown, J. Bjarnason, A. Fedor, T. Korter, On the strong and narrow absorption signature in lactose at $0.53 \mathrm{THz}$, Appl. Phys. Lett. 90 (6) (2007). 061908-3.

[41] J.K. Euna Jung, Han Younho, M.L.H.H. Kiwon Moon, Terahertz time domain spectroscopy of crystalline $\alpha$-lactose monohydrate, Biochip J. 2 (4) (2008) 296-299.
[42] D. Allis, A. Fedor, T. Korter, J. Bjarnason, E. Brown, Assignment of the lowestlying $\mathrm{THz}$ absorption signatures in biotin and lactose monohydrate by solidstate density functional theory, Chem. Phys. Lett. 440 (4) (2007) 203-209.

[43] Y. Shen, P. Taday, M. Pepper, Elimination of scattering effects in spectral measurement of granulated materials using terahertz pulsed spectroscopy, Appl. Phys. Lett. 92 (5) (2008) 051103.

[44] J.A. Zeitler, K. Kogermann, J. Rantanen, T. Rades, P.F. Taday, M. Pepper, et al., Drug hydrate systems and dehydration processes studied by terahertz pulsed spectroscopy, Int. J. Pharm. 334 (1-2) (2007) 78-84.

[45] J.F. Willart, V. Caron, R. Lefort, F. Danède, D. Prévost, M. Descamps, Athermal character of the solid state amorphization of lactose induced by ball milling, Solid State Commun. 132 (10) (2004) 693-696.

[46] M. Otsuka, H. Ohtani, N. Kaneniwa, S. Higuchi, Isomerization of lactose in solid-state by mechanical stress during grinding, J. Pharm. Pharmacol. 43 (3) (1991) 148-153.

[47] J. Sibik, S. Elliot, J.A. Zeitler, Thermal decoupling of molecular-relaxation processes from the vibrational density of states at terahertz frequencies in supercooled hydrogen-bonded liquids, J. Phys. Chem. Lett. (2014) 1968-1972.

[48] S. Taraskin, S. Simdyankin, S. Elliott, J. Neilson, T. Lo, Universal features of terahertz absorption in disordered materials, Phys. Rev. Lett. 97 (5) (2006) 055504. 